\title{
Congenital Urethral Diverticulum in Male Subject: Report of Three Cases
}

\author{
Yaya Sow1, Babacar Sine1, Ibrahima Dara Diamé2, Ndéye Aissatou Bagayogo1, Amath Thiam1, \\ Denis Barboza ${ }^{3}$, Alioune Sarr'1, Cyrille Zé Ondo', Boubacar Fall1, Babacar Diao1 \\ ${ }^{1}$ Urology Andrology Department of Artistide Le Dantec Hospital, Dakar, Senegal \\ ${ }^{2}$ Ourassogui Hospital, Matam, Senegal \\ ${ }^{3}$ De La Paix Hospoital, Ziguinchor, Senegal \\ Email: papesine@yahoo.fr
}

How to cite this paper: Sow, Y., Sine, B. Diamé, I.D., Bagayogo, N.A., Thiam, A., Barboza, D., Sarr, A., Ondo, C.Z., Fall, B. and Diao, B. (2018) Congenital Urethral Diverticulum in Male Subject: Report of Three Cases. Open Journal of Urology, 8, $43-48$.

https://doi.org/10.4236/oju.2018.82005

Received: January 4, 2018

Accepted: February 20, 2018

Published: February 23, 2018

Copyright $\odot 2018$ by authors and Scientific Research Publishing Inc. This work is licensed under the Creative Commons Attribution International License (CC BY 4.0).

http://creativecommons.org/licenses/by/4.0/

\begin{abstract}
Introduction: The urethral diverticulum or urethrocele corresponds to a saccular dilation of a portion of the urethral wall. Our objective was to report the clinical aspects, investigations and therapeutic aspects of three cases of congenital urethrocele. Observations: They were three male patients aged 11, 20 and 42 years, two of whom had consulted for terminal dribbling. The diagnosis of urethrocele was made for all patients with retrograde and voiding cystouretrography. Treatment consisted of resection of the urethrocele followed by urethroplasty for both cases. Conclusion: Diagnostic of congenital urethrocele must always be assessed when there is a persistent terminal dribbling, and systematically ask for a Retrograde Cysto-Urethrography (RCUG) to confirm it.
\end{abstract}

\section{Keywords}

Urethra, Diverticulum, Congenital, Male, Diverticulectomy

\section{Introduction}

The urethral diverticulum or urethrocele corresponds to a saccular dilation of a portion of the urethral wall. Urethral diverticulum has been observed at any age. The primary diverticulum of the urethra or congenital urethral diverticulum in man is a rare finding. This rate is lower than reported by some authors who evaluated the incidence of urethral diverticula between $0.5 \%$ and $6 \%$ [1] [2], with a female predominance. The acquired form is far more frequent than the congenital primary diverticulum [3]. We describe congenital urethral diverticulum type in three male patients followed up in our department. 


\section{Case Series}

Case 1:

This was a 20-year-old man, single without children, having consulted for terminal dribbling without other associated signs and without any notion of trauma evolving four years before. This symptomatology prompted a consultation in the department of urology-andrology of Dantec. These signs required treatment with antibiotics and oxybutynin without improvement. The clinical examination was normal. Urinalysis and ultrasound of the urinary tract were also normal. However, a Retrograde Cysto-Urethrography (RCUG) has been performed and has demonstrated a radiological aspect in favor of a diverticulum of the bulbar urethra (Figure 1). Thus, the indication of a resection of the diverticulum was made. At exploration, there was a diverticulum of the bulbar urethra of about $1.5 \mathrm{~cm}$ with a large collar about $2 \mathrm{~cm}$ in diameter. An ureterocelectomy was performed and urethroplasty with PDS 4/0 suture on a Ch18 catheter. The follow up were marked by an infection of the operative site at day 8 (D8). The cyto-bacteriological examination of pus isolated Pseudomonas aeruginosa sensitive to amikacin and imipenem. The patient was thus treated with amikacin $1 \mathrm{~g}$ for seven days. Suppuration ceased and complete healing was obtained 21 days after surgery. The catheter was removed two months after surgery. He was seen in consultation and had no obstructed urination.

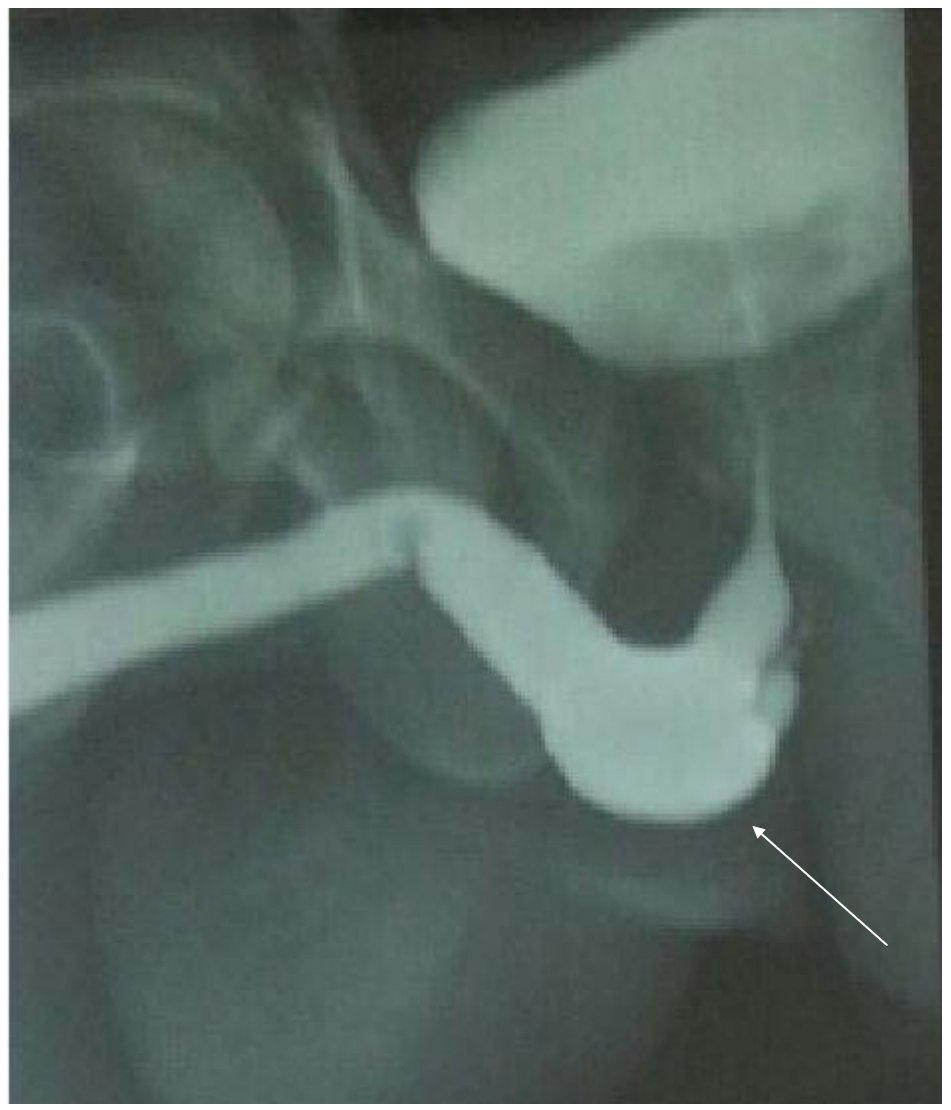

Figure 1. RCUG showing sub-urethral addition image (head of arrow). 


\section{Case 2:}

Mr. G, aged 40 years consulted for terminal dribbling evolving for 3 years associated with frequent urination during the day without a history of trauma. He has had several treatments in different health facilities. The additional examinations performed were normal. These included urinalysis, chlamydia and mycoplasma serology and urinary tract ultrasound. At first, he had a treatment with alpha-blockers (Doxasosin) for three months without improvement of the symptoms. He then received an anticholinergic and observed a reduction in the frequency of urination. After 5 months he had a complete urine retention which required drainage of the urine by a Foley catheter for 48 hours and a stoppage of the anticholinergic. This is how the patient was oriented in our department where retrograde cystourethrography (RCUG) was performed and showed an addition image on the bulbo-perineal urethra in relation to an urethrocele (Figure 2). Exploration showed a bulbar urethrocele about $4 \mathrm{~cm}$ long with a collet of $2 \mathrm{~cm}$. An ureterocelectomy was thus performed plus urethroplasty with vicryl 4/0 on a Ch18 catheter. The surgical follow-up was simple and removal of the catheter was performed at D10 postoperative. The patient was lost sight of.

Case 3:

It was K. S, an 11-year-old boy who consulted in our department for terminal dribbling and micturition burns without any other associated signs without a history of trauma evolving since early childhood. Physical examination showed a micturating intermittent swelling in the ventral side of the penis. The RCUG showed an addition image on the posterior penile urethra (Figure 3). At exploration, there was a diverticulum about $4 \mathrm{~cm}$ long with a collar $3 \mathrm{~cm}$ in diameter. A diverticulectomy was performed and then an urethroplasty on a Ch12 catheter. Removal of the catheter was performed postoperatively at D10. The patient was reviewed at 6 months postoperatively, he had no obstructed urination and the postoperative RCUG did not find the image in favor of a diverticulum.

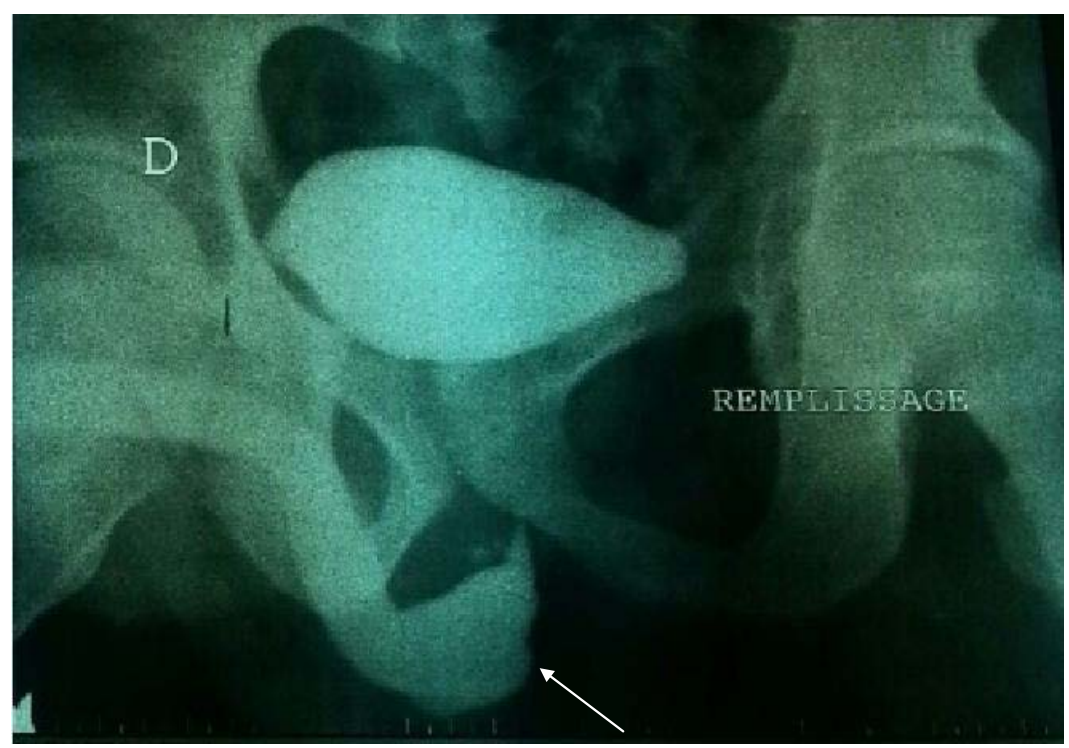

Figure 2. RCUG showing sub-urethral addition image (head of arrow). 




Figure 3. RCUG showing sub-urethral addition image (head of arrow).

\section{Discussion}

All our patients consulted for terminal dribbling, the diagnosis was confirmed by RCUG. They all had urethoplasty after resection of the diverticulum.

The etiopathogenesis of the congenital primary diverticulum rests on various theories, including that of Hancen, which reports the possibility of the urethral diverticulum occurring by cystic dilatations of the canaliculi of the Cowper glands; Or the Maingel syringocele [4]. For others, the congenital diverticulum represents the expression of an embryological abnormality by abnormal development of the urethral plate and fusion of the genital folds. But other mechanisms of occurrence have been reported by Orikasa et al. [5]. These are dilated para-urethral glands, urethral duplication, and ectopic urethra.

A congenital diverticulum can manifest at any age [1]. It can evolve long and often prove to be complicated. This is why it was noted in two of our patients at 22 and 40 years. Moreover, its large volume can be responsible for urinary symptoms which make consult early enough; it is the case of our patient who was 11 years old.

The symptoms of the post-voiding phase, namely delayed drops, are the most frequently reported clinical signs. Indeed two of our patients had consulted for delayed drops. Urinary symptoms are not specific to the type of diverticulum. This clinical expression depends, in fact, on the size of the diverticulum and the existence or absence of an infection [6] [7].

The diverticula sat at the level of the anterior urethra in all our patients. This same seat has been reported by several authors including Benjelloun [1] and Monish et al. [8]. However, localizations at the posterior urethra have been described [9]. In our study, all patients had diverticula with collar deemed large. The width of the collar is a determining factor in the choice of the management method [10]. 
The diagnosis of congenital diverticulum of the urethra is based on its radiological opacification during RCUG. The urethral diverticulum appears as an oval image added to the urethra of variable size [11]. This classic image has been demonstrated in all our patients as well as in several published cases [8]. RCUG also makes it possible to look for other congenital malformations that may associate with the urethral diverticulum. These malformations are hypospadias, the valves of the posterior urethra [12].

The value of magnetic resonance imaging is proven in women with a diverticulum under urethral and its use is increasing for the diagnosis of male urethral diverticula Similarly, Computed Tomography or Excretory urogram have the same indication, that is, the search for associated urogenital malformation.

Malignant transformation of the urethral diverticulum has also been described hence the interest of the histological examination of the diverticulectomy piece.

From the therapeutic point of view, the cure of the anterior diverticulum is well codified. In the case of a narrow collar on the urethra intact, resection of the diverticulum at the collar with urethrography in a single time remains the best attitude [10]. On the other hand, in the case of a large collar and urethra of poor quality, some authors propose a flattening and the urethral reconstitution will be done in the second time after 3 to 6 months [9]. The treatment of the diverticulum of the posterior urethra is based on perineal or pre pubic diverticulum resection [7]-[12]. Some authors advocate for asymptomatic forms that the treatment is based on the manual pressure of the urethra at the level of the diverticulum at the end of urination and the use of periodic antibiotic prophylaxis to prevent infections [12].

Urethral diverticulum surgery is relatively simple; however, it can be followed by complications. They may be of fistula type by necrosis of the banks, suture release and infection of the operative site [1]-[6]. This is the case in patient 2 who had infection of the operative site and then an urethro-cutaneous fistula which required a longer duration of catheterism.

\section{Conclusion}

These three observations highlight the diagnostic aberrations that have delayed the management of our patients. It is undoubtedly the rarity of the condition that explains these diagnostic difficulties. Diagnostic of congenital urethral diverticulum must always be assessed when there is persistent delayed drops and systematically ask for a Retrograde Cysto-Urethrography (RCUG) to confirm it.

\section{References}

[1] Benjelloun, M., Rabii, R., Guessous, H., Essaki, H., Bennani, S. and EL Mrini, M. (2003) Diverticule de l'urèthre post-traumatique chez l'adulte. Progrès Urologie, 13, 506-508.

[2] Marya, S.K.S. and Shavinder, K. (1980) Acquiered Male Urethral Diverticulum. Journal of Urology, 124, 350-355. https://doi.org/10.1016/S0022-5347(17)55443-9

[3] Rimon, U., Hertz, M. and Jonas, P. (1992) Diverticula of the Male Urethra: A Re- 
view of 61 Cases. Urologic Radiology, 14, 49-55.

https://doi.org/10.1007/BF02926901

[4] Menendez, V., Puyol, M. and Talbot-Wright, R. (1995) Diverticulo Uretral Congenito. Actas Urológicas Españolas, 19, 651.

[5] Orikasa, S., Metoki, R., Ishikawa, H. and Arai, M. (1990) Congenital Urethral and Vesical Diverticula Allied to Blend-Ending Ureteres. Urology, XXXV, 137-141. https://doi.org/10.1016/0090-4295(90)80062-R

[6] Ortlip, S.A., Gonzalez, R. and Williams, R.D. (1980) Diverticula of the Male Urethra. Journal of Urology, 124, 350. https://doi.org/10.1016/S0022-5347(17)55443-9

[7] Mohan, V., Gupta, S.K. and Cherian, J. (1980) Urethral Diverticulum in Male Subject: Report of 5 Cases. Journal of Urology, 124, 350. https://doi.org/10.1016/S0022-5347(17)55443-9

[8] Monish, A., Rajeev, T.P., Dorairajan, L.N. and Gupta, N.P. (1999) Infected Congenital Urethral Diverticulum in an Adult Male. Urologia Internationalis, 62, 177-179. https://doi.org/10.1159/000030386

[9] Dmochowski, R. (2001) Urethral Diverticula: Evolving Diagnostics and Improved Surgical Management. Current Urology Reports, 2, 373-378. https://doi.org/10.1007/s11934-996-0023-Z

[10] Auvigne (1981) Ablation des diverticules. Encycl. Med. Chir., Article ID: 41330.

[11] Ryu, J. and Kim, B. (2001) MR Imaging of the Male and Female Urethra. Radiographics, 21, 1169-1185. https://doi.org/10.1148/radiographics.21.5.g01se121169

[12] Ockrim, J.L., Allen, D.J., Shah, P.J. and Greenwell, T.J. (2009) A Tertiary Experience of Urethral Diverticulectomy: Diagnosis, Imaging and Surgical Outcomes. BJU International, 103, 1550-1554. 